\title{
Comprehensive in silico functional specification of mouse retina
} transcripts

\author{
Samuel Shao-Min Zhang*1,2, Xuming $\mathrm{Xu}^{1,2}$, Jinming $\mathrm{Li}^{3}$, Mu-Gen Liu ${ }^{1,2}$, \\ Hongyu Zhao ${ }^{3,4}$, M Bento Soares ${ }^{5}$, Colin J Barnstable ${ }^{2,6}$ and Xin-Yuan Fu ${ }^{1}$
}

\begin{abstract}
Address: ${ }^{1}$ Departments of Pathology, Yale University School of Medicine, 310 Cedar Street, New Haven, CT 06520, USA, ${ }^{2}$ Departments of Ophthalmology and Visual Science, Yale University School of Medicine, 330 Cedar Street, New Haven, CT 06520, USA, ${ }^{3}$ Department of Epidemiology and Public Health, Yale University School of Medicine, 60 College Street, New Haven, CT 06520, USA, ${ }^{4}$ Department of Genetics, Yale University School of Medicine, 333 Cedar Street, New Haven, CT 06520, USA, ${ }^{5}$ Departments of Pediatrics, Biochemistry, Orthopaedics, Physiology and Biophysics, The University of Iowa Roy J. and Lucille A. Carver College of Medicine, 375 Newton Road, Iowa City, IA 52242, USA and ${ }^{6}$ Department of Neurobiology, Yale University School of Medicine, 333 Cedar Street, New Haven, CT 06520, USA
\end{abstract}

Email: Samuel Shao-Min Zhang* - shao-min.zhang@yale.edu; Xuming Xu - xuming.xu@yale.edu; Jinming Li - JMLi@ntu.edu.sg; MuGen Liu - mugen.liu@yale.edu; Hongyu Zhao - hongyu.zhao@yale.edu; M Bento Soares - bento-soares@uiowa.edu;

Colin J Barnstable - colin.barnstable@yale.edu; Xin-Yuan Fu - xfu@exchange.iupui.edu

* Corresponding author

Published: 18 March 2005

BMC Genomics 2005, 6:40 doi:10.1 186/147|-2164-6-40
Received: 23 November 2004

Accepted: 18 March 2005

This article is available from: http://www.biomedcentral.com/I47I-2/64/6/40

(C) 2005 Zhang et al; licensee BioMed Central Ltd.

This is an Open Access article distributed under the terms of the Creative Commons Attribution License (http://creativecommons.org/licenses/by/2.0), which permits unrestricted use, distribution, and reproduction in any medium, provided the original work is properly cited.

\begin{abstract}
Background: The retina is a well-defined portion of the central nervous system (CNS) that has been used as a model for CNS development and function studies. The full specification of transcripts in an individual tissue or cell type, like retina, can greatly aid the understanding of the control of cell differentiation and cell function. In this study, we have integrated computational bioinformatics and microarray experimental approaches to classify the tissue specificity and developmental distribution of mouse retina transcripts.

Results: We have classified a set of retina-specific genes using sequence-based screening integrated with computational and retina tissue-specific microarray approaches. 33,737 nonredundant sequences were identified as retina transcript clusters (RTCs) from more than 81,000 mouse retina ESTs. We estimate that about 19,000 to 20,000 genes might express in mouse retina from embryonic to adult stages. $39.1 \%$ of the RTCs are not covered by 60,770 RIKEN full-length cDNAs. Through comparison with 2 million mouse ESTs, spectra of neural, retinal, late-generated retinal, and photoreceptor -enriched RTCs have been generated. More than $70 \%$ of these RTCs have data from biological experiments confirming their tissue-specific expression pattern. The highest-grade retina-enriched pool covered almost all the known genes encoding proteins involved in photo-transduction.
\end{abstract}

Conclusion: This study provides a comprehensive mouse retina transcript profile for further gene discovery in retina and suggests that tissue-specific transcripts contribute substantially to the whole transcriptome. 


\section{Background}

The retina is a well-defined portion of the Central Nervous System (CNS) that has long been used as a model for CNS development and function [1-4]. It is susceptible to a variety of diseases that can lead to vision loss or complete blindness. Most of the unique functions of the retina depend upon its tissue-specific transcript sets, suggesting that a systematic definition of retinal transcripts would be an invaluable approach to understanding retinal cell identities and functions.

The complete genome sequences of human and mouse provide a new starting point for understanding specific expressed transcripts, especially the sequences associated with development and disease. Expressed sequence tag (ESTs) databases, are the most abundant resource of gene expression data. Recently, Okazaki et al. used available data on ESTs to establish a comprehensive full-length transcript data base [5]. There have been a number of studies of retinal transcripts [6-10] and initial databases listing some of the retinal transcripts ([11]; http:// neibank.nei.nih.gov/index.shtml; [12]; http:// www.umich.edu/ igene/), but none of these have provided a global view of retinal transcripts. Recently, Blackshaw et al used serial analysis of gene expression (SAGE) identified 1,051 genes that showed developmentally dynamic expression in mouse retina [13]. Schulz and coworkers analyzed a set of retina transcripts from a mixed population of different datasets and suggested that about 13,000 transcripts might describe $90 \%$ of the adult retinome [14]. Although a systemic analysis of mouse retina ESTs has recently been reported $[15,16]$, the functional specification of retina transcripts has not. Thus, this study provides a complementary view of mouse retina transcripts.

In the present study, we have generated mouse retina ESTs from embryonic day 13.5 (E13.5), postnatal day 1 (PN1), and adult ( 8 weeks old) and then analyzed about 81,000 ESTs along with other three major mouse retina libraries through an approach that integrates computational and retina tissue-specific microarray data to identify a set of candidate genes highly related to retina-specific function and retinal diseases. 33,737 non-redundant sequences were identified as retina transcript clusters (RTCs) and step by step classified into neural, retinal, late-generated retinal, and photoreceptor-enriched RTCs. This study also provides a comprehensive table of mouse retina transcript profiles that will now allow a better understanding of retinal development and function.

\section{Results \\ Purification and specification of mouse RTCs}

We used a series of computational steps (Fig. 1, Additional data file 1 and 2) to clean up and reorganize a total

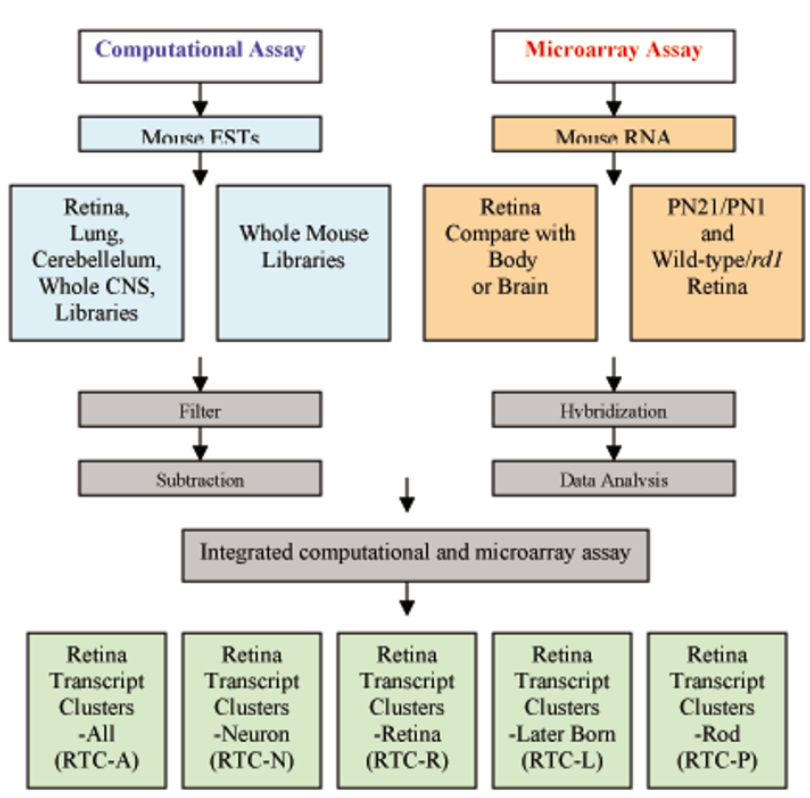

Figure I

Scheme of computational and biological procedures. For computational analysis, five mouse EST sets were used (retina, cerebellum, lung, CNS, and whole EST). All ESTs were filtered through a non-redundant procedure (details in additional data file I and 2). The whole set of RTCs representing all retina transcripts was called RTC-All (RTC-A). Then RTC-A were subtracted with CNS and whole mouse ESTs to generate RTC-N and RCT-R pool. Cleaned cerebellum and lung EST pool were used as internal control. In microarray assays, tissues from PN2I mouse retina, brain, and other body regions were used for comparison of gene expression to verify RTC-R. Gene expression profiles from PN2 I/PNI retina comparisons represented a set of genes involved in late-born retina development. By comparison of this set with RTC-R, RTC related to late-born retina cell development were generated (RTC-L). PN35 wild-type retina was used to compare with $r d /$ mutant retina at same age. Results from this subtraction represent a set of genes whose expression is associated with rod photoreceptors (RTC-P).

of 81,253 mouse retina ESTs from the NCBI database (October 2002). The starting pool of retina ESTs was generated from the total retina ESTs by subtraction of a population $(4,848$ or $5.9 \%$ of the total) containing repeat sequences, fusion sequences, low sequence quality, vector sequences, very short sequences, mitochondrial sequences, and sequences with no BLAST-hit in the mouse genome (data not shown). 33,737 ESTs from this starting pool of 76,467 were identified by applying a program that searched for non-redundant sequences (Fig. 2A). We have termed these Retina Transcript Clusters (RTCs). 

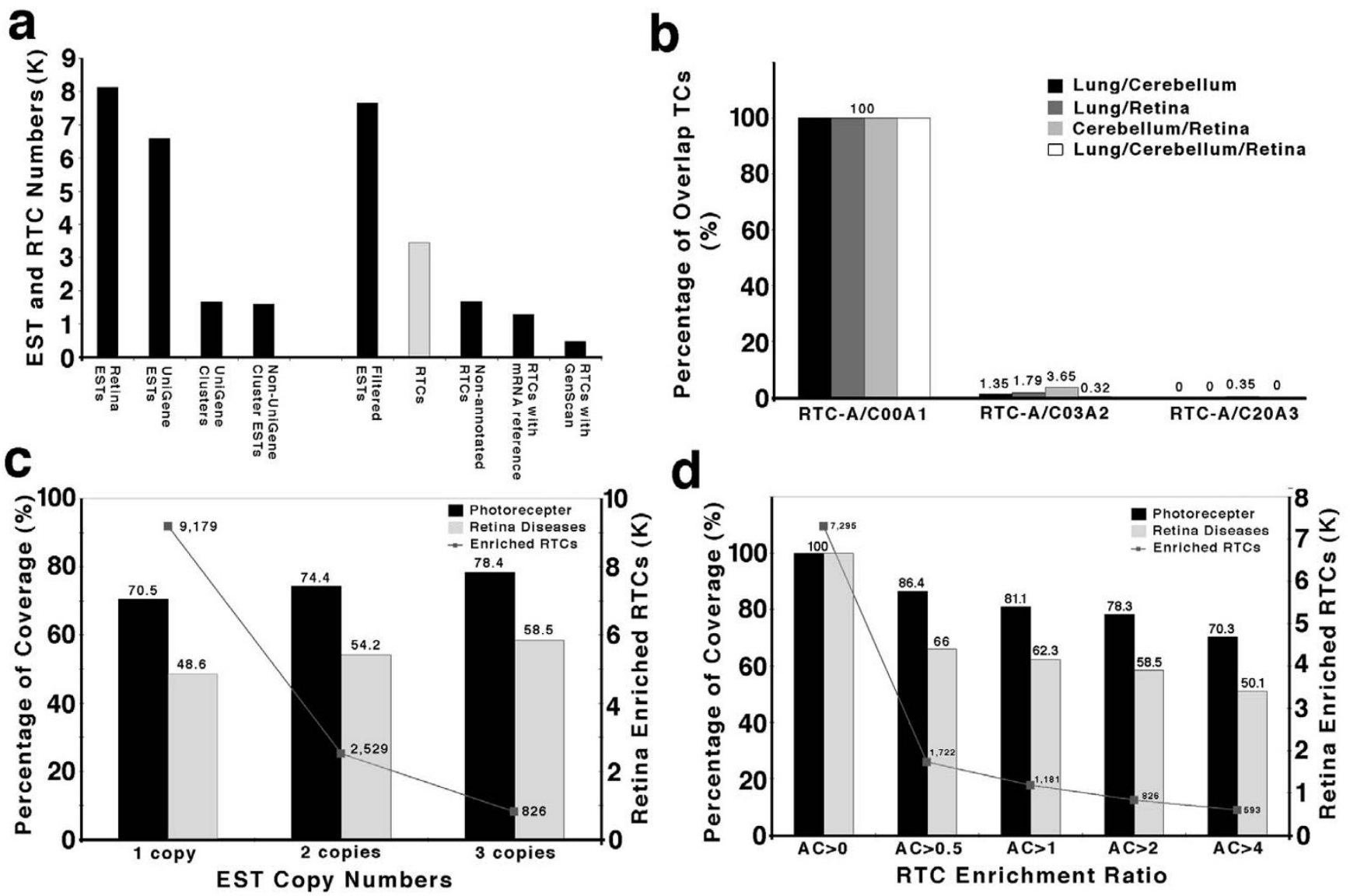

Figure 2

Purification and classification of mouse retina ESTs. (a) Distribution of retina ESTs in different categories. Total numbers of ESTs in mouse retina libraries; ESTs clustered by UniGene; Numbers of UniGene clusters; ESTs not clustered by UniGene; filtered ESTs for TC classification; retina transcript clusters (RTCs); Numbers of RTCs only represented in ESTs (nonannotated RTCs); Numbers of RTCs represented in mRNA references; and Numbers of RTCs represented in GenScan. (b) The percentage of overlap UniGene clusters between two different tissues or among three different tissues at distinct subtraction grades. (c and d) The coverage rates of known retina disease genes in retina libraries at different EST copy numbers and distinct subtraction grades. photoreceptor, photoreceptor related genes; Retina diseases, known retina disease genes; Enriched RTCs, retina specific and enriched RTCs.

Among the RTCs, 12,939 (37.4\%) have a reference RNA sequence in the NCBI database $\mathrm{ftp} / / / \mathrm{ftp} . n c b i . n i h . g o v / r e f$ seq/, 4,825 (13.9\%) have no reference RNA sequence but do have GenScan [17] predicted sequence information, and 16,494 (47.7\%) are pure EST (Fig. 2A). The whole set of RTCs was further analyzed by comparing their sequences (BLAST score $>=100$ ) with 60,770 RIKEN mouse full-length cDNAs derived from multiple tissues [5]. 39.1\% of the RTCs were not present in the RIKEN mouse full-length pool, indicating the existence of a substantial population with either unique full-length or uniquely spliced transcripts in retina.
To find criteria by which we could define tissue-enriched or tissue-specific transcript clusters we carried out a comparative analysis starting with approximately 106,000 lung and 80,000 cerebellum ESTs. These sequence pools were filtered using the same procedures as for retina to give transcript clusters (TCs) for each tissue. We then collected all the sets of mouse EST data and removed from them any set that would contain a contribution from retina, lung or cerebellum. This gave a set of data containing over 2 million ESTs. We then used this total EST dataset and the individual transcript clusters (TCs) to derive a ratio for the number of copies in each TC compared with 
the number in the total. Any EST in a TC that was not found in the total was set to a value of 100. An EST with 5 copies in a TC and 5 copies in the total would have a ratio of 1 and an EST with 10 copies in a TC and 5 in the total would have a ratio of 2 . This analysis was carried out for each of the three TCs. We then asked at what ratio were ESTs in the RTC not found in either the LTC or the CTC using the subset of sequences for which fell into UniGene clusters. At a ratio of 0.3 and above only $1.79 \%$ of RTC were shared with lung and only $3 \%$ with cerebellum (Fig $2 \mathrm{~B})$. By increasing the ratio to 2, the overlap with lung fell to $0 \%$ and with cerebellum fell to $0.3 \%$.

We have also examined abundance in the EST pool as a criterion for helping define tissue specific transcripts. As a reference for the validity of these criteria we tested the inclusion of a known set of 47 known photoreceptor genes. Using an enrichment ratio of 2 from the above analysis, we found that $70-80 \%$ of these known photoreceptor specific genes were included in the RTCs. By increasing the copy number to 2 or more or to 3 or more, the total pool of RTCs decreased from 9,179 to 2,629 and 826 respectively without any substantial loss of detection of the known photoreceptor specific genes (Fig 2C). The pool of 826 RTCs is listed in Additional data file 3.

We also carried out this analysis by setting the copy number to $>3$ and examining the effect of varying the enrichment ratios (Fig 2D). At this copy number, increasing the enrichment ratio above 0.5 only changed the coverage and total number of ESTs by small amounts. Trend tests of the reduction of RTC numbers associated with increased EST copy number were significant using photoreceptor related genes $\left(P=6.8 \times 10^{-59}\right)$ as criteria. Together our analysis suggests that about $80 \%$ of tissuespecific or -enriched transcripts can be identified using the two criteria, a copy ratio of at least two in the specific tissue and at least three EST copies.

\section{Biological approach in identification of enriched retina transcripts}

We also tested the biological robustness of the computational data using mouse retina tissue-specific microarrays (9,216 spots and 7,612 UniGene clusters) for experimental confirmation. Two groups of experiments were designed to detect genes enriched in retina or photoreceptors by microarray analysis. In the first group, total RNA from postnatal day 21 (PN21) retina was isolated and compared with RNA from whole brain or pooled RNA from other organs, including heart, lung, spleen, liver, and kidney from the same animals, (designated as "body" in this study). The data from Retina/Body, Retina/Brain were analyzed individually and $\log 2$ ratio results of the two experiments are shown as a spot-plot graph (Fig. 3A). The Retina/Body ratio is represented along the $\mathrm{Y}$-axis and the
Retina/Brain ratio along the $\mathrm{X}$-axis. When setting $\log 2>=$ 1 as positive ratio, a double positive population lying at the upper-right represents retina-enriched genes. Using the same protocol, for the second group of experiments we compared RNA from PN21 retina with RNA from PN1 retina as set 1 (PN21retina/PN1retina) and PN35 wildtype retina with PN35 rd-1 (photoreceptor-deficient) retina as set 2 (WTretina/rd1retina). In set 1 we are comparing retinas before and after the generation of rod photoreceptors and in set 2 we were comparing wild type retinas with retinas in which the rods had degenerated. Thus, when setting $\log 2>=1$ as positive ratio, a double positive gene population lay at the upper-right and was considered as rod-enriched genes (Fig. 3B). The microarray results were used to generate two gene-expression profiles specific for later born neurons of retina and photoreceptors, respectively (Additional data file 4).

Computationally enriched ESTs from retina (RTC-R), subtracted with whole body and neuron ESTs, were compared with the microarray data from Retina/Body and Retina/ Brain. The overlap between the two approaches was $70 \%$ under the microarray criterion of $\log 2$ ratio $>=1$ (Fig. 3C, 316 RTCs, $P=6.1 \times 10^{-5}$ ) and $80 \%$ using the criterion of 1.5 (Fig. 3D, 148 RTCs, $P=10^{-4}$ ). The percentage of overlap increased by increasing the EST copy number (Fig. 3C and $3 \mathrm{D})$, indicating that the accuracy of the enriched detection in specific tissues depends on the EST copy numbers, reflective of mRNA abundance.

\section{Functional clusters of retina enriched RTCs}

RTCs were further specified as RTC-A (RTC-all retina transcripts), RTC-N (RTC-neuron enriched transcripts), RTC-R (RTC-retina enriched transcripts), RTC-L (RTC-late-born retina cell enriched transcripts), and RTC-P (RTC-photoreceptor enriched transcripts) using the methods described in Figures 1 and additional data file 1. The number of RTCs in individual RTC categories is shown in Figure 4A. RTCs that were present in the Gene Ontology (GO) database [18] were used for functional clustering. As shown in Figure 4B within the Biological Process category, a significant population (10\% to $20 \%$ ) in the subcategory Response to External Stimulus is found in RTC-L and RTC-P. The majority of RTCs in this category are the genes related to light response.

To determine whether the enriched TCs of different tissues contained different functional clusters, we analyzed the EST populations of lung, cerebellum, and retina that are in the GO database. About 45 functional clusters from the Biological Process and Molecular Function categories of the GO database were analyzed before subtraction and about 30 functional clusters were analyzed after subtraction and the results shown in radar graphs. Interestingly, before subtraction, a similar distribution of functional clusters 

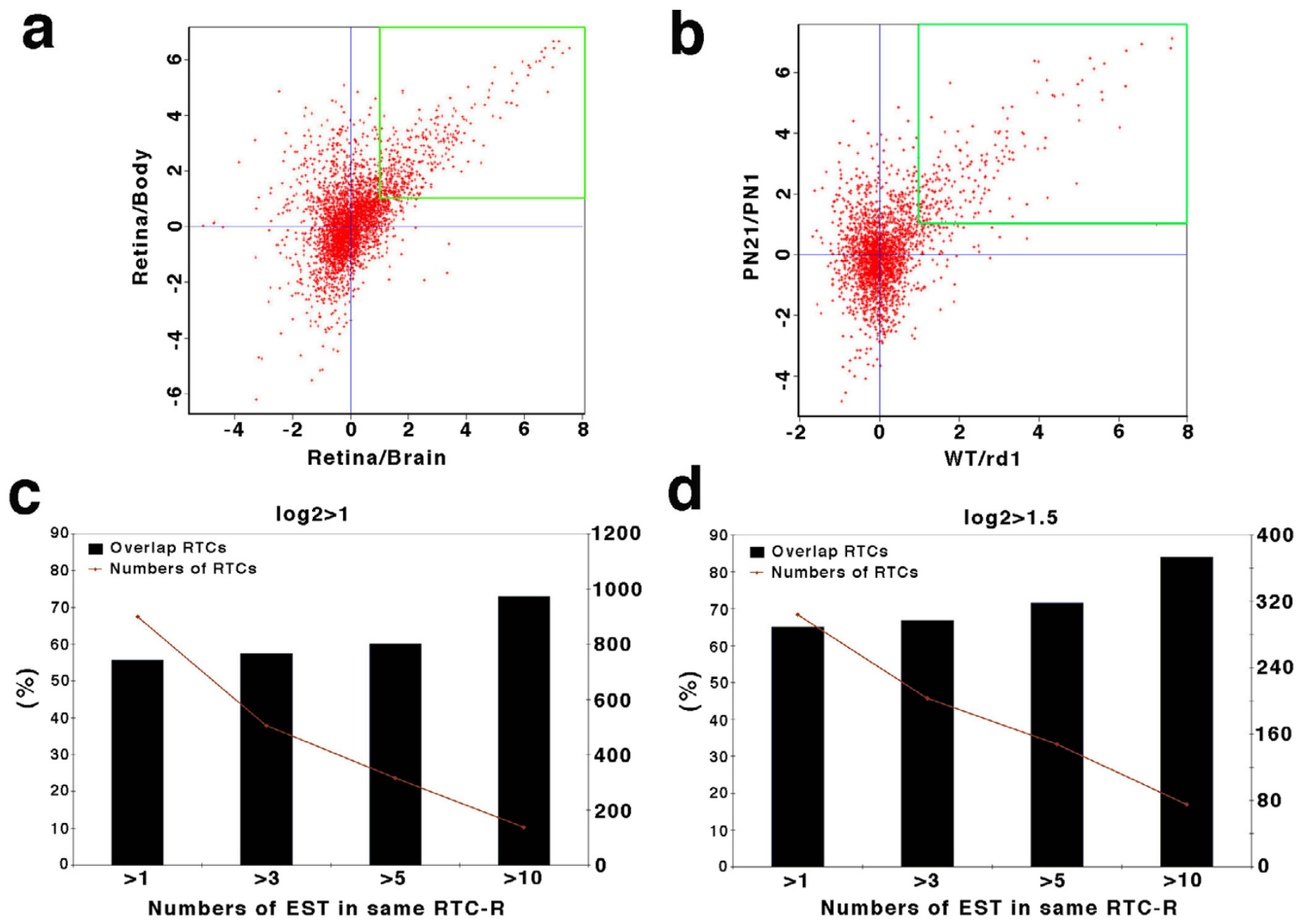

Figure 3

Microarray approach and confirmation of retina enriched RTCs. (a) Spot-plot graph of microarray data from Retina/ Brain and Retina/Body. Log2 ratio is used for comparison. Overlap populations on upper-right were retina specific/enriched genes. (b) Spot-plot graph of microarray data from PN2 I/PNI and WT/rdI. Log2 ratio is used for comparison. Overlap populations in upper-right were photoreceptor specific/enriched genes. (c and d) The percentage (bar-graph) of RTCs overlapping between computational assay (RTC-R) and microarray assay at distinct microarray ratio, $\log 2=\mathrm{I}(\mathrm{C})$ and log2 = I.5 (D). Line represents the numbers of RTCs. X-axis is copy number in same RTCs.

appeared among the three libraries in either Biological Process (Fig. 4C) or Molecular Function (data not shown) categories. After subtraction, using the criteria of $>3$ EST copies and an enrichment ratio of 2, the distribution of functional clusters shifted in specific directions in Biological Process (Fig. 4D, Table 1) categories. This suggests that using subtracted subsets for classification of ESTs in individual tissues can provide accurate information about functional specificities.

We also looked at distinct functional profiles at an early phase (embryo) including E13.5, E14.5, and PN1 and an adult phase, using the criteria of $>3$ copies RTCs and $83 \%$ (ratio $>5$ ) enrichment in one phase compared to the other (Fig 4E and 4F). We found, that in retina-enriched RTC-pools (826 RTCs, > 3 EST copies, 2 fold enrichment) the majority of the RTCs were found in both phases (495 RTCs, $59.9 \%$ ). 34.4\% (284 RTCs) were found only in the adult phase, and 5.7\% (47 RTCs) were found only in the embryo phase.

To examine the different functional clusters in these two phases, categories of the GO database were analyzed. In the biological process category, $18 \%$ of RTCs belonged to Cell Organization and Biogenesis clusters and 12\% to Cell Cycle clusters in the embryo phase compared with $6 \%$ and $5 \%$, respectively, in the adult phase. Conversely, about $24 \%$ of RTCs were in the Transport clusters in the adult 
a

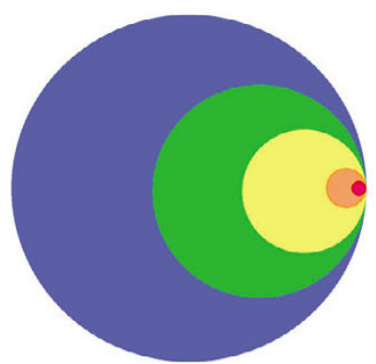

\section{Distribution of RTCs}

C

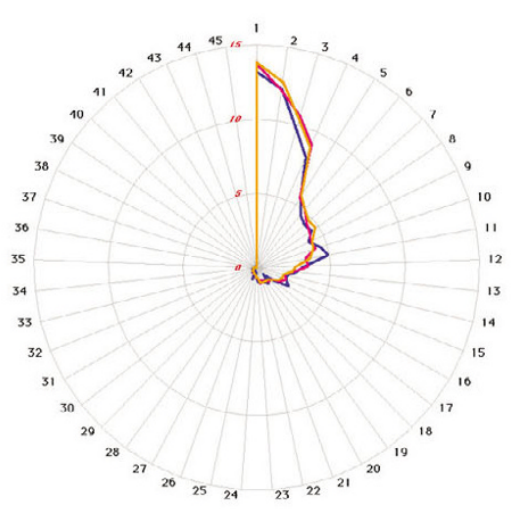

Before subtraction

e

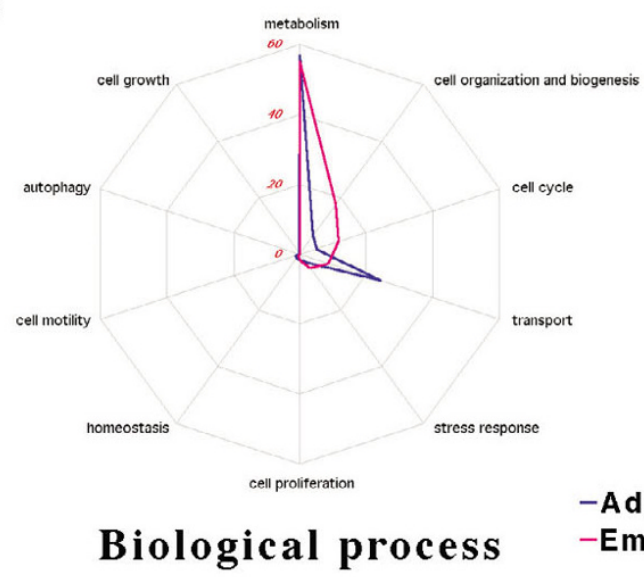

RTC-A $(33,474)$

RTC-N $(11,318)$

RTC-R $(3,985)$

RTC-L (654)

RTC-P (234)
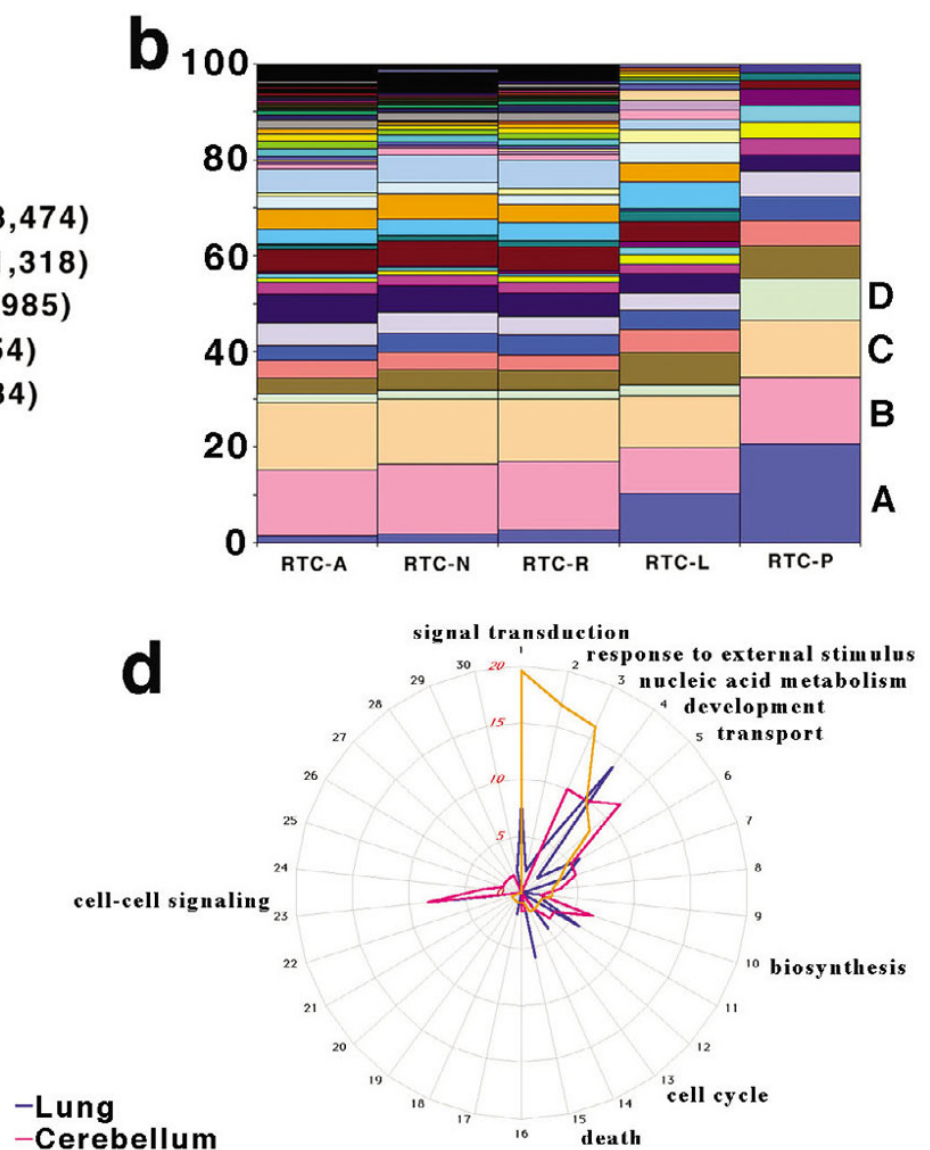

-Cerebellum Retina

After subtraction

f

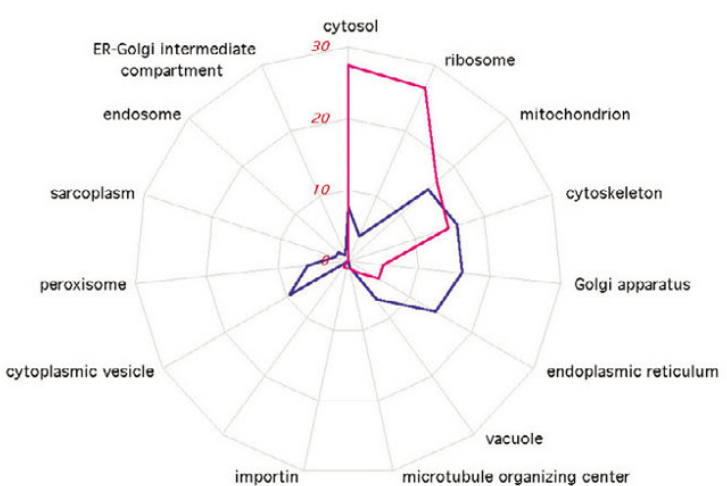

Cellular component

\section{Figure 4}

GO analysis before and after RTC subtraction. (a) Distribution of RTCs in distinct categories (details described in text). (b) Functional annotation in distinct categories. $A$, perception of external stimulus; $B$, nucleobase, nucleoside, nucleotide and nucleic acid metabolism; $C$, protein metabolism and modification; $D$, carbohydrate metabolism; $E$, ion transport; $F$, protein transport; $G$, organogenesis; $H$, catabolism; I, biosynthesis; J, electron transport; $K$, energy pathways; $L$, amino acid and derivative metabolism; $M$, cytoplasmic transport; N, phosphate metabolism; $O$, hydrogen transport. (c and d) Subcategories of Biological Process category Functional clusters of TCs in lung (blue line), cerebellum (red line), and retina (yellow line) before (C) and after (D) subtraction. (e and f) Functional clusters of RTCs enriched in adult (blue line) or in embryonic phase (red line). Subcategories of Biological Process category (E) and of Cellular Component category (F). 
Table I: Comparison of Functional Clusters in Three Tissue Specific or Enriched EST Pools*

\begin{tabular}{|c|c|c|c|}
\hline & Retina & Lung & Cerebellum \\
\hline GO:0007I54 cell communication (total gene numbers) & 36 & 8 & 16 \\
\hline GO:0009605 response to external stimulus & 19 & I & 0 \\
\hline GO:000958I perception of external stimulus & 18 & 0 & 0 \\
\hline GO:0009628 response to abiotic stimulus & 18 & 0 & 0 \\
\hline GO:00093 14 radiation response & 18 & 0 & 0 \\
\hline GO:00094I6 light response & 18 & 0 & 0 \\
\hline GO:0009582 perception of abiotic stimulus & 18 & 0 & 0 \\
\hline GO:0009583 perception of light & 18 & 0 & 0 \\
\hline GO:000959I perception of mechanical stimulus & 1 & 0 & 0 \\
\hline GO:0009592 perception of sound & I & 0 & 0 \\
\hline GO:0007600 sensory perception & 17 & 0 & 0 \\
\hline GO:000760I vision & 17 & 0 & 0 \\
\hline GO:0007605 hearing & I & 0 & 0 \\
\hline GO:0007609 mechanosensory perception & I & 0 & 0 \\
\hline GO:0009607 response to biotic stimulus & 2 & 0 & 0 \\
\hline GO:0007I55 cell adhesion & 4 & 2 & 3 \\
\hline GO:0016337 cell-cell adhesion & 1 & 0 & 1 \\
\hline GO:0007165 signal transduction & 22 & 4 & 9 \\
\hline GO:0007I 66 cell surface receptor linked signal transduction & 10 & 3 & 4 \\
\hline GO:0007I67 enzyme linked receptor protein signaling pathway & I & 0 & 0 \\
\hline GO:0007I86 G-protein coupled receptor protein signaling pathway & 8 & 0 & 3 \\
\hline GO:0007I87 G-protein signaling, coupled to cyclic nucleotide second messenger & I & 0 & I \\
\hline GO:0008277 regulation of G-protein coupled receptor protein signaling pathway & I & 0 & 0 \\
\hline GO:00072 12 dopamine receptor signaling pathway & 0 & 0 & I \\
\hline GO:00072I 4 gamma-amino butyric acid signaling pathway & 0 & 0 & I \\
\hline GO:0016055 Wnt receptor signaling pathway & I & 3 & I \\
\hline GO:0007223 frizzled-2 receptor signaling pathway & 0 & 3 & 0 \\
\hline GO:0007242 intracellular signaling cascade & 8 & 0 & 4 \\
\hline GO:0019932 second-messenger-mediated signaling & 1 & 0 & I \\
\hline GO:0007243 protein kinase cascade & i & 0 & 0 \\
\hline GO:0007264 small GTPase mediated signal transduction & 1 & 0 & 0 \\
\hline GO:0007267 cell-cell signaling & 0 & 3 & 5 \\
\hline GO:0019226 transmission of nerve impulse & 0 & 0 & 4 \\
\hline GO:0007268 synaptic transmission & 0 & 0 & 4 \\
\hline GO:000I505 neurotransmitter maintenance & 0 & 0 & I \\
\hline GO:0008037 cell recognition & 1 & I & 0 \\
\hline
\end{tabular}

* Cell communication category is used for this table. Tissue specific or enriched EST pools are under condition of $66 \%$ concentrated in individual libraries and at least three EST copies. There are no overlap of genes among each libraries.

phase and only $8.5 \%$ in the embryo phase (Fig. 4E). Although there was the same percentage in Metabolism clusters (Fig. 4E) in both the embryo (55\%) and adult (56\%) phases, detailed analysis showed that about $17 \%$ of RTCs were in Biosynthesis clusters in the embryo phase compared with $7.7 \%$ in the adult phase (Fig. $4 \mathrm{~F}$ ). Interestingly, Lipid metabolism (5.8\%) and Energy pathways (3.9\%) were significantly higher in adult phase and in embryo phase, respectively. As expected, overall comparison of these phases shows a change from functions characteristic of a proliferating epithelium (such as cell cycle) to those characteristic of a mature retina (such as transport).

\section{A comprehensive transcript profile of mouse retina}

The computational processes described above classified a total of 33,737 RTCs for their statistical probability of being retina specific or retina-enriched, as listed in Additional data file 5 . Because of the possibility of alternative splicing, we did not combine all UniGene clusters together and kept the non-redundant sequences as our cluster units. Thus, there may be some gene redundancy in the 33,737 RTCs. If we ignore this potential redundancy among the RTCs, 25,673 RTCs can be clustered into 14,618 UniGene clusters (57\%) and 8,064 RTCs have not yet been clustered. If we assume the same ratio of RTCs to clusters for un-clustered RTCs, we estimate that about 19,000 to 20,000 genes might expressed in mouse retina from embryonic to adult stages.

Seven sets of information are provided in the additional data file 5. First, a set of basic information including RTC I.D. numbers, Genbank I.D. for reference sequences, locus 
Table 2: Information of Known Homeodomain Contained Genes from RTCs

\begin{tabular}{|c|c|c|c|c|c|c|c|c|c|c|c|}
\hline Symbl & $\%$ & D/E (\%) & E/D (\%) & $\mathbf{A}$ & C & RTCs & UniGene & Gene Name & MmChr & HsChr & Ref \\
\hline Crx & 98.7 & 99.9 & 0.1 & 74 & I & BU503524 & Mm.8008 & cone-rod homeobox containing gene & chr7 & $\operatorname{chrl9}$ & y \\
\hline Dlxl & 50 & 0 & 100 & I & 2 & BG808909 & Mm.4543 & distal-less homeobox I & $\operatorname{chr} 2$ & chr2 & y \\
\hline Dlx2 & 100 & 0 & 100 & 1 & 0 & BG805973 & Mm.3896 & distal-less homeobox 2 & chr2 & chr2 & $\mathrm{n}$ \\
\hline Hhex & 5.6 & 100 & 0 & 1 & 17 & BB709075 & Mm.33896 & hematopoietically expressed homeobox & $\operatorname{chr} 19$ & chrlo & $\mathrm{n}$ \\
\hline $\mathrm{Hmxl}$ & 100 & 0 & 100 & 3 & 0 & BE949806 & Mm.10104 & H6 homeo box I & $\operatorname{chr} 5$ & chr4 & y \\
\hline Hoxc4 & 5.9 & 100 & 0 & I & 16 & BB283935 & Mm.|35I & homeo box $\mathrm{C} 4$ & $\operatorname{chrl5}$ & $\operatorname{chrl} 2$ & $\mathrm{n}$ \\
\hline Hoxc8 & 20 & 100 & 0 & I & 4 & BB283726 & Mm.6167 & homeo box $\mathrm{C} 8$ & $\operatorname{chrl5}$ & $\operatorname{chrl} 2$ & $\mathrm{n}$ \\
\hline Irx2 & 1.4 & 0 & 100 & 2 & 139 & BG80I773 & Mm.28888 & Iroquois related homeobox 2 (Drosophila) & $\operatorname{chrl3}$ & chr5 & $\mathrm{n}$ \\
\hline Irx3 & 5.7 & 0 & 100 & 2 & 33 & BE951617 & Mm.39039 & Iroquois related homeobox 3 (Drosophila) & chr8 & $\operatorname{chrl6}$ & $\mathrm{n}$ \\
\hline $\operatorname{lr} \times 5$ & 6.8 & 0 & 100 & 5 & 69 & BE949849 & Mm.10II53 & Iroquois related homeobox 5 (Drosophila) & chr8 & & y \\
\hline $\operatorname{lr} \times 6$ & 100 & 100 & 0 & 1 & 0 & BG298876 & Mm. I37247 & Iroquois related homeobox 6 (Drosophila) & chr8 & $\operatorname{chrl6}$ & y \\
\hline$|s| \mid$ & 20.6 & 38.5 & 61.5 & 14 & 68 & BF467775 & Mm.42242 & ISLI transcription factor, LIM/homeodomain, (islet-I) & $\operatorname{chrl3}$ & chr5 & $\mathrm{n}$ \\
\hline Lhxl & I7.| & 100 & 0 & 3 & 17 & BB283776 & Mm.4965 & LIM homeobox protein I & chrll & $\operatorname{chrl7}$ & $\mathrm{n}$ \\
\hline Lhx2 & 9.7 & 33.3 & 67.7 & 7 & 65 & BF46276I & Mm. 142856 & LIM homeobox protein 2 & $\operatorname{chr} 2$ & $\operatorname{chr} 9$ & $y$ \\
\hline Lhx3 & 66.7 & 100 & 0 & 12 & 6 & BE986454 & Mm. I5655 & LIM homeobox protein 3 & $\operatorname{chr} 2$ & chr9 & $\mathrm{n}$ \\
\hline Lhx4 & 66.7 & 100 & 0 & 2 & I & BG297508 & Mm. 103624 & LIM homeobox protein 4 & chrl & chrl & $\mathrm{n}$ \\
\hline Lhx9 & 30 & 0 & 0 & 3 & 7 & BE982I 77 & Mm.79380 & LIM homeobox protein 9 & chrl & chrl & $\mathrm{n}$ \\
\hline Nkx6-2 & 3.8 & 67.7 & 33.3 & 7 & 175 & BE949669 & Mm.28308 & NK6 transcription factor related, locus 2 (Drosophila) & chr7 & $\operatorname{chrl0}$ & $\mathrm{n}$ \\
\hline Og9x & 80 & 100 & 0 & 4 & I & $\mathrm{BI} 736847$ & Mm. I42724 & OG9 homeobox gene & chrll & & $\mathrm{n}$ \\
\hline Onecutl & 33.3 & 0 & 100 & I & 2 & BG805378 & $M m .3512$ & one cut domain, family member I & chr9 & $\operatorname{chrl5}$ & $\mathrm{n}$ \\
\hline Onecut3 & 100 & 0 & 0 & 1 & 0 & BE9953I4 & Mm.221027 & one cut domain, family member 3 & $\operatorname{chrl0}$ & $\operatorname{chr} 19$ & $\mathrm{n}$ \\
\hline Otx2 & 42.9 & 100 & 0 & 9 & 12 & BG4044I 3 & $M m .134516$ & orthodenticle homolog 2 (Drosophila) & $\operatorname{chrl} 4$ & $\operatorname{chrl} 4$ & y \\
\hline Pax6 & 44.2 & 65.4 & 34.6 & 46 & 49 & BQ930I62 & Mm.3608 & paired box gene 6 & $\operatorname{chr} 2$ & chrll & $y$ \\
\hline Pknoxl & 4.5 & 0 & 0 & I & 21 & BM94I536 & Mm.87619 & Pbx/knotted I homeobox & $\operatorname{chrl7}$ & chr2I & $\mathrm{n}$ \\
\hline Pknox2 & 37.5 & 0 & 100 & 3 & 5 & BG803I56 & Mm.4I577 & Pbx/knotted I homeobox 2 & $\operatorname{chr} 9$ & chrll & $\mathrm{n}$ \\
\hline Proxl & 60 & 100 & 0 & 6 & 4 & BM940687 & Mm.20429 & prospero-related homeobox I & chrl & chrl & $y$ \\
\hline Prrxl & 14.3 & 100 & 0 & 2 & 12 & BB283 |4I & Mm.3869 & paired related homeobox I & chrl & chrl & $\mathrm{n}$ \\
\hline $\operatorname{Rax}$ & 100 & 66.7 & 33.3 & 12 & 0 & BB642844 & Mm.3499 & retina and anterior neural fold homeobox & $\operatorname{chrl8}$ & $\operatorname{chrl8}$ & y \\
\hline Sixl & 2.6 & 100 & 0 & 1 & 37 & BB2839|4 & Mm.4645 & sine oculis-related homeobox I homolog (Drosophila) & $\operatorname{chrl} 2$ & $\operatorname{chr} 14$ & $\mathrm{n}$ \\
\hline Six 3 & 76.9 & 0 & 100 & 10 & 3 & BG807874 & Mm. I5630 & sine oculis-related homeobox 3 homolog (Drosophila) & $\operatorname{chrl7}$ & chr2 & y \\
\hline Six 6 & 86.7 & 42.9 & 57.1 & 13 & 2 & $\mathrm{~B} 1990712$ & Mm.57I38 & sine oculis-related homeobox 6 homolog (Drosophila) & $\operatorname{chrl} 2$ & $\operatorname{chrl} 4$ & $y$ \\
\hline $\operatorname{Vax} 2$ & 50 & 0 & 100 & I & I & $\mathrm{B} 1989827$ & Mm.57253 & ventral anterior homeobox containing gene 2 & chr6 & $\operatorname{chr} 2$ & $y$ \\
\hline Vsxl & 100 & 100 & 0 & 4 & 0 & BB642331 & Mm.20706I & visual system homeobox I homolog (zebrafish) & $\operatorname{chr} 2$ & & $y$ \\
\hline Zfh4 & 100 & 100 & 0 & 3 & 0 & BB642530 & Mm.4I522 & zinc finger homeodomain 4 & chr3 & chr8 & $\mathrm{n}$ \\
\hline Zfhxla & 10.1 & 42.9 & 57.1 & 8 & 71 & BE954320 & Mm.3929 & zinc finger homeobox la & $\operatorname{chrl8}$ & chrlo & $\mathrm{n}$ \\
\hline Zfhxlb & 10.7 & 100 & 0 & 3 & 25 & $\mathrm{BI} 7302 \mid 4$ & Mm.37676 & zinc finger homeobox $\mathrm{Ib}$ & chr2 & chr2 & $\mathrm{n}$ \\
\hline Zhxl & 75 & 100 & 0 & 3 & I & BG404047 & Mm.37216 & zinc fingers and homeoboxes protein I & chrl5 & chr8 & $\mathrm{n}$ \\
\hline
\end{tabular}

$\%$, percentage of RTCs distributed in retina

A, RTCs; C, filtered mouse ESTs

D/E (\%), percetage of RTCs in adult phase; E/D (\%), percetage of RTCs in embryonic phase

$\mathrm{MmChr}$, mouse chromosome; $\mathrm{HsChr}$, human chromosome

Ref, genes have been study in retina $(y)$ or not $(n)$

link numbers, UniGene numbers and descriptions; second, chromosomal locations in the mouse (UCSC, $\mathrm{mm} 2$, Feb 2002) and human (UCSC, hg13, Nov, 2002) genomes including start and end points within the UCSC golden-path database; third, information about TC numbers in whole mouse ESTs, whole mouse retina libraries, adult retina, and embryonic retina libraries; fourth, ratio of RTC enrichment compared with whole mouse ESTs, whole ESTs from neuronal libraries, and also a comparison between RTC from adult and embryonic libraries; fifth, RTC enriched patterns under different enrichment criteria; sixth, published SAGE information from Black- shaw et al [6], and seventh, human retina transcript information from RetBase [7].

Using the RTC database, we can identify new genes specifically expressed or enriched in the retina for which there is not yet any biological evidence. For example, a total of 37 known genes with homeodomains from the RTC pool are listed in Table 2. Some of the genes have been well studied like Crx [19,20], Rax [21], Otx2 [22,23], and Prox1 [24]. Most of these genes, however, have not previously been described in retina, such as Og9x [25], Lhx [26,27], and Onecut $[28,29]$. Three of the sine oculis (so)/Six family of 
a

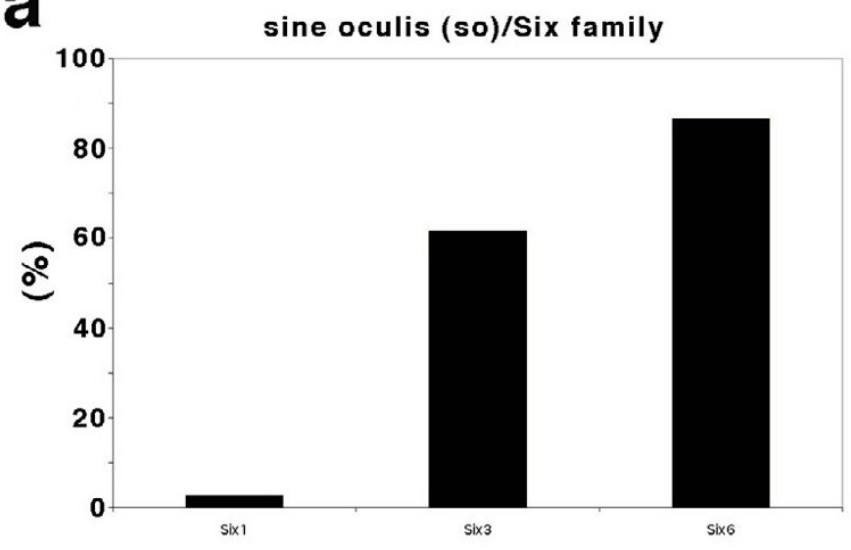

C

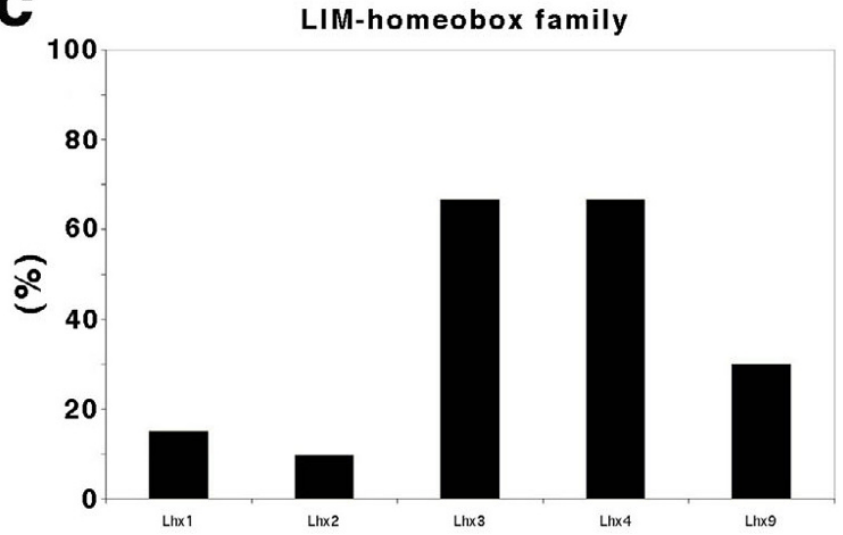

b

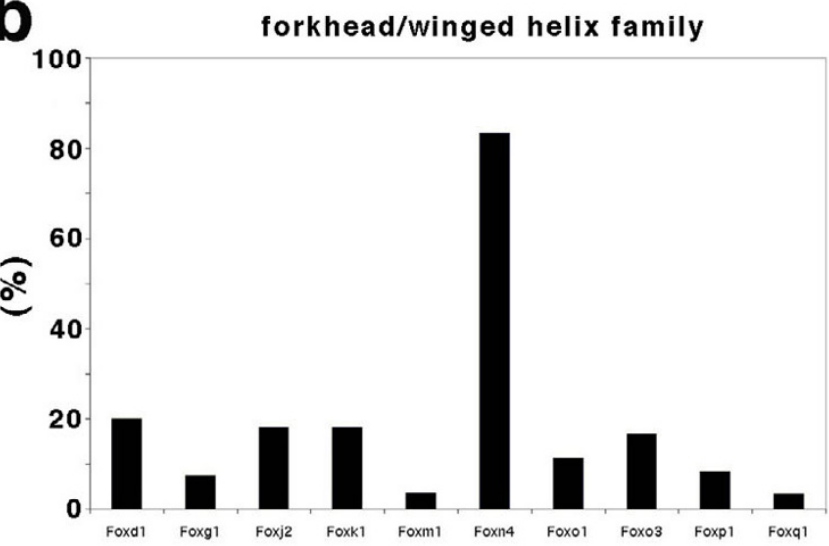

d

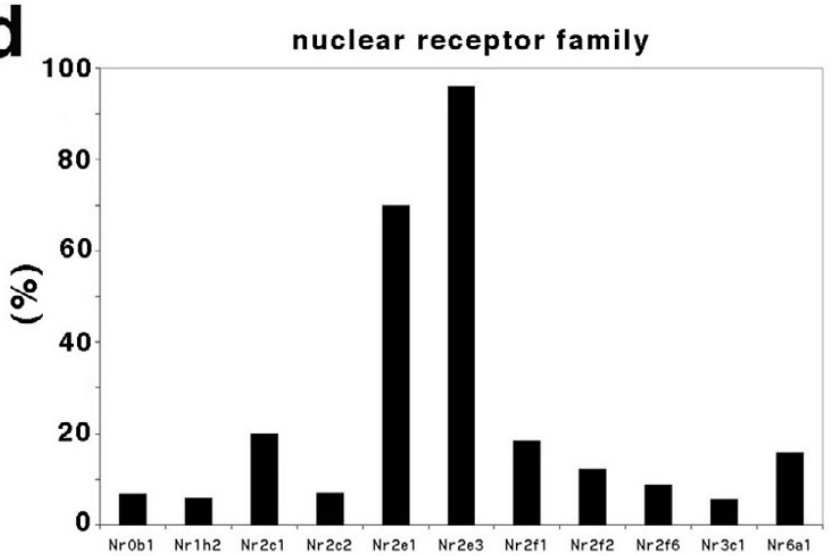

Figure 5

Distribution of enriched RTCs in gene families. (a) The percentage of enriched RTCs of sine oculis (so)/Six family in retina. (b) The percentage of enriched RTCs of forkhead/winged helix family in retina. (c) The percentage of enriched RTCs of LIM-homeobox family in retina. (d) The percentage of enriched RTCs of nuclear receptor family in retina.

genes were present in the RTC pool (Fig. 5A). ESTs of Six3 and Six 6 were $60 \%$ to $80 \%$ enriched in retina. The patterns have been confirmed by biological studies of expression level [30] and function analysis [31-33] of these genes. Ten members of forkhead/winged helix family appeared in our RNA pools and only one, Foxn 4 is highly concentrated in the retina (Fig. 5B). This observation has also been confirmed by a recent study [34]. The genes from those two gene families are highly enriched in the embryo phase. Lhx3 and Lhx4, from the LIM homeodomain gene family, are highly enriched in the adult retina (Fig. 5C). Similarly, genes such as those encoding members of the guanine nucleotide binding protein family, the ATP-binding cassette protein family, the voltagedependent calcium channel protein family, and the potassium voltage-gated channel protein family (additional data file 6) are also present in the retina enriched pool. We do not have biological evidence for all the genes that have been listed in this comprehensive profile of RNAs expressed in retina, yet our gene-tables can be useful tools for analyzing mouse retina transcripts and can provide an overview of genes involved in function and development of retina.

From the RTC database, we can also extract identify candidate genes for human retinal diseases. As shown in Figure $2 \mathrm{C}$, using the criteria of enrichment ratio $>2$ and at least 3 EST copies in RTC, 826 RTCs were identified as a retina enriched gene pool. By homology with the human genome, this RTC pool covers about $80 \%$ of knownphotoreceptor related genes (29 out of 37, Fig. 2C and 2D). Through comparison with individual interval gene numbers, numbers of candidate RTCs are concentrated to $1.5 \%$ to $0.05 \%$ (additional data file 7 ). A full list of known human retina disease genes and the subtraction information are shown in additional data file 8 . Among retina-dis- 
Table 3: Comparison of predicted retina enriched genes by different system

\begin{tabular}{lllll}
\hline & Sage7l & Sage264 & RetBase374 & RTCI84 \\
\hline Sage7I & $\mathbf{7 1 ( 1 0 0 )}$ & $29(40.8) 5(7)$ & $22(30.9)$ & $15(5.7)$ \\
Sage264 & $29(10.9)$ & $\mathbf{2 6 4 ( 1 0 0 )}$ & $4(1.5)$ & $14(3.7)$ \\
Retbase374 & $5(1.3)$ & $4(1.1)$ & $\mathbf{3 7 3}(100)$ & $100)$ \\
RTCI84 & $22(11.9)$ & $15(8.2)$ & $14(7.6)$ & $184(100)$ \\
\hline
\end{tabular}

Sage 7I, 2 out of 4 (Blackshow et al, 200I)

Sage264, (Blackshow et al, 200I)

RetBase374, (Katsanis et al. 2002)

ease-related genes, almost all photoreceptor related genes especially the genes involved in phototransduction processes are covered by our most stringent subtraction and selection criteria (> 3 EST copies and 2 fold enrichment). However, genes related to systemic diseases or syndromes, genes involved in RNA processing and genes with lower copy numbers in RTCs are not present under these criteria, indicating a limitation of this method. Although candidate genes from the 826 RTCs pool can cover over 41 of 48 mapped human retina disease loci, here we provide only the genes for 27 loci that have been more stringently associated with primarily photoreceptor disorders (additional data file 7 and 9).

Comparison with other approaches for retina enriched gene subtraction shows obvious gaps among the various experimental approaches (Table 3 ). Here we have compared our enriched gene pool with the pools from SAGE [6] and RetBase [7]. Only genes clustered by UniGene are used using two criteria from SAGE pool with two standards [6], 2 out of 4 (71 genes) and SAGE 264 (264 genes) respectively; one criteria from Retbase (373 genes, [7]); and one criteria with at least 3 EST copies and 2 fold enrichment in RTCs (184 genes). The highest 22\% overlaps between our and SAGE pools and the lowest $5 \%$ overlaps between Retbase and SAGE pools.

\section{Discussion}

The full specification of transcripts in an individual tissue or cell type can greatly aid the understanding of the control of cell differentiation and cell function. In the present study, we have integrated computational bioinformatics and microarray experimental approaches to classify the tissue specificity and developmental distribution of mouse retina transcripts.

We have defined 33,737 retina transcript clusters (RTCs) as single units with non-redundant sequences, although multiple transcript clusters can be in the same UniGene cluster. Such RTCs may represent different parts of a gene, or splice variants that are not considered in the UniGene database. We have calculated that about 19,000 to 20,000 genes may be expressed during mouse retina development from embryonic day 13.5 to adult. This is about $30 \%$ more compared with Schulz's Retinome (13,037 genes) [14], although this was restricted to transcripts in the adult phase. Since the nervous system, including the retina, has more prolific RNA splicing (2.5 fold higher that other tissues) [35], we suggest that the numbers of unique transcripts found in retina may well be greater than 20,000 . More interestingly, since $39.1 \%$ of the RTCs are not included in the most comprehensive mouse fulllength transcript set made by RIKEN [5], tissue-specific transcripts and splicing may constitute a substantial proportion of the whole transcriptome. On the other hand, there are large numbers of ESTs (about 16,000) that do not appear to encode proteins. Many of these may serve as regulatory RNA or have other unknown functions and need further study $[5,13]$.

A major concern for specification of transcripts from ESTs is how to confirm a reliable result. We have used four control steps to verify the results. First, as an external negative control we compared the specificity in our target tissue, retina, and in other tissues (lung and cerebellum). Second, we used an internal positive control. We used known photoreceptor-specific genes to check their coverage rate during different steps of retina specification. The third control was to identify functional clusters through the Gene Ontology (GO) database before and after specification of ESTs in different tissues. Biological confirmation was the final control experiment in this study and used a mouse retina tissue-specific microarray. Results from all the control experiments fully support the conclusions of this study.

Identification of retina disease genes is an important and immediate use for genome-wide study tools. Several approaches have been used for genome-wide hunting of such genes. However, as shown in our results, the data sets show obvious gaps among these various experimental approaches (Table 3 ). Katsanis et al performed subtraction against 1.4 million human ESTs with 40,000 human retinal ESTs by a series of computational tools. They 
found a total of 925 ESTs likely to be specifically or preferentially expressed in the retina [7]. We found a low overlap between RetBase and our enriched pools. In part this is because of the smaller starting sample, the majority of human ESTs are generated from tumors and the emphasis on single copy sequences in the RetBase set. A SAGE analysis identified 264 uncharacterized genes that were specific to or highly enriched in rods [6-9]. This data set showed more overlap with our results but there are, still obvious gaps among these various experimental approaches, so we suggest that integrating different approaches might be much more valuable for tissue specific and enriched gene prediction.

Generation and specification of an entire transcription profile for individual tissues or cells with specific functions and morphologic identities represents the next major task in the genome era. In conclusion, this study complements and extends previous studies in a number of ways. First, we have generated a comprehensive data set of retina transcript profiles with functional and developmental explanation, as the examples shown in Figure 4 and Table 2, diverse function information can be generated through our RTC profiles that will now allow a better understanding of retinal development and function. It is not only for hunting retina disease genes, but also for understanding of gene developmental distribution. Second, this study has classified retina transcripts into different grades of retinal specificities that will help us define them as common, neural specific or retinal specific genes. Third, the distinct approaches of this study will allow an easy updating of our mouse retina transcripts databases in future.

\section{Methods}

\section{EST resources and manipulation}

Mouse retina ESTs were collected from NCBI and were filtered and cleaned up by a series of programs (Figures 1, S1 and S2). Two Dell Precision WorkStation 530's running RedHat 7.0 Linux were used for computational processes. The database used was MySQL and the languages for programming were Python, GNU C, awk, and bash. Repeat detection used RepeatMasker http://repeatmas ker.genome.washington.edu/cgi-bin/RepeatMasker (kindly provided by A. Smith and P. Green). Other analyses used custom programs.

\section{Mice and retina sample collection}

Mice were purchased from the Jackson Laboratory $(\mathrm{C} 57 \mathrm{Bl} / 6 \mathrm{j})$ or were a gift from Dr. C. Zeiss, Yale University (C3H $w t$ and $r d 1$ ). Retinas were dissected without contamination from lens, iris, cornea, and ciliary body. 10 to 20 retinas or other organs were pooled for RNA isolation. All animal experiments were conducted in accordance with
NIH guidelines and were approved by the IACUC of Yale University School of Medicine.

\section{RNA preparation}

Total RNA was isolated by TRIzol (Invitrogen) and purified by RNeasy mini kit (QIAGEN). $5 \mu \mathrm{g}$ total RNA with 280/260 ratios greater than 1.9 was used for array hybridization without amplification. Three to four sets of RNA were prepared from each age of retina and processed individually for microarray analysis.

\section{Microarray experiments}

About 12,000 non-redundant mouse retina ESTs were generated from about 28,000 ESTs that generated from E13.5, PN1 and adult (The NIH-University of Iowa Brain Molecular Anatomy Project). 9,216 purified PCR-amplified inserts were printed by the Yale Keck Microarray Core on poly L-Lysine (Sigma) coated glass slides utilizing a GeneMachines Omnigrid robotic arrayer (GeneMachines). 3DNA Submicro EX Expression Array Detection Kits (Genisphere, PA) were used for RNA labeling. Detailed microarray experimental protocols are shown in supplemental methods. Slides were scanned on a GenePix $4000 B$ scanner and the data were manipulated with GenePix software Version 4.0 (Axon Instruments). Three or four sets of microarray data for each experiment were used for Student $\mathrm{t}$ test and gene collection. Gene collection methods are described in text and also please see additional data file 10 for methods detail.

\section{Statistics}

To test whether the features illustrated in Figures 2 and 3 show an increasing trend in terms of covering photoreceptor related genes and retina disease genes through more stringent filtering criteria, we conducted trend tests in the following form: $T=\sum_{i=1}^{C} w_{i} y_{i}$, where $C$ is the number of classes above the baseline total population, $w_{i}$ is the weight for the $i$ th class, and $y_{i}$ is the observed percentage related to the feature of interest in the $i$ th class. The value of $C=2,4,3$, and 3 , for figures $2 \mathrm{C}, 2 \mathrm{D}, 3 \mathrm{C}$, and $3 \mathrm{D}$, respectively. The value of $y_{i}$ is the proportion of the ESTs with a given feature in the $i$ th class, with the feature being either a photoreceptor related gene or a retina disease gene. The weights are $1,2, \ldots, \mathrm{C}$ for the $\mathrm{C}$ classes.

To assess the statistical evidence of a trend in the data based on $T$, we calculated the mean and variance of $T$ under the null hypothesis of no trend conditional on the feature distribution in the baseline total population. It can be shown that when the feature of interest is binary, i.e. a given EST either has or does not have this feature, 
$E(T)=\sum_{i=1}^{C} w_{i} y_{0}$ and $\operatorname{Var}(T)=\left(\sum_{i=1}^{C} \beta_{i}\right) y_{0}\left(1-y_{0}\right)-\sum_{i=1}^{C} \beta_{i} v_{i}$,

where

$\beta_{i}=\left(\sum_{j=i}^{C} w_{j}\right)^{2} \frac{N_{i-1}-N_{i}}{N_{i-1}-1} \frac{1}{N_{i}}, v_{1}=0, v_{i+1}=\left(1-\alpha_{i}\right) v_{i}+\alpha_{i} \gamma_{0}\left(1-\gamma_{0}\right)$, for $i \geq 1, \alpha_{i}=\frac{N_{i-1}-N_{i}}{N_{i-1}-1} \frac{1}{N_{i}}$,

$N_{i}$ is the number of ESTs in the $i$ th class, $N_{0}$ is the number of ESTs in the total population, and $y_{0}$ is the proportion of ESTs having a given feature in the total population. The statistical significance of the observed increasing trend is

$$
1-\Phi\left(\frac{T-E(T)}{\sqrt{\operatorname{Var}(T)}}\right)
$$

and the statistical significance of the observed decreasing trend is

$\Phi\left(\frac{T-E(T)}{\sqrt{\operatorname{Var}(T)}}\right)$

where $\Phi$ is the cumulative function of the standard normal distribution. Statistic calculations were done by $\mathrm{R}$ 1.8.1 or R 1.7.1. http://cran.us.r-project.org

\section{List of abbreviations}

RTC, Retina Transcript Cluster; CNS, Central Nervous System; EST, Expressed Sequence Tag; GO, Gene Ontology; PN, Postnatal

\section{Authors' contributions}

SSMZ was primarily responsible for the design, coordination, conduct, and all experiments of the studies. XYF and CJB were responsible for coordination of the studies. XX and JL were responsible for computational data analyses and software development. SSMZ and MGL were responsible for microarray experiments and analysis. MGL and $\mathrm{HZ}$ were responsible for statistical analysis. SSMZ, MBS, and XYF were responsible for RNA collection and original initiation and generation of mouse retina ESTs. SSMZ and CJB drafted the manuscript and figures. All authors read and approved the final manuscript.

\section{Additional material}

\section{Additional File 1}

Methods for in silico purification of ESTs.

Click here for file

[http://www.biomedcentral.com/content/supplementary/14712164-6-40-S1.doc]

\section{Additional File 2}

Methods for in silico specification of RTCs.

Click here for file

[http://www.biomedcentral.com/content/supplementary/14712164-6-40-S2.doc]

\section{Additional File 3}

RTC list under criteria of RTC-A/C20A3.

Click here for file

[http://www.biomedcentral.com/content/supplementary/14712164-6-40-S3.xls]

\section{Additional File 4}

Gene list of RTC-L and RTC-P.

Click here for file

[http://www.biomedcentral.com/content/supplementary/1471-

2164-6-40-S4.xls]

\section{Additional File 5}

Whole RTC information and SAGE, RetBase data comparison. Click here for file

[http://www.biomedcentral.com/content/supplementary/1471-

2164-6-40-S5.xls]

\section{Additional File 6}

Samples of the percentage of RTCs in different gene families. $\boldsymbol{a}_{\text {, Heterot- }}$ rimeric guanine nucleotide-biding proteins. $\boldsymbol{b}$, ATP-binding cassette $(A B C)$ transporter superfamily. $c$, Voltage-dependent calcium channel proteins. $\boldsymbol{d}$, Voltage-gated potassium channel proteins.

Click here for file

[http://www.biomedcentral.com/content/supplementary/14712164-6-40-S6.jpeg]

\section{Additional File 7}

Candidate genes for human retina disease loci. a, Gene numbers of chromosome interval and concentrated retina enriched gene pool in human known retina disease gene loci. $\boldsymbol{b}$, Concentrated ratio between retina enriched gene pool and whole interval genes of the loci for human known retina disease gene. c, Gene numbers of chromosome interval and concentrated retina enriched gene pool in some human known retina disease loci. $d$, Concentrated ratio between retina enriched gene pool and whole interval genes of the loci for human retina disease.

Click here for file

[http://www.biomedcentral.com/content/supplementary/14712164-6-40-S7.jpeg]

\section{Additional File 8}

Known human retina disease gene list used in this study. Click here for file

[http://www.biomedcentral.com/content/supplementary/14712164-6-40-S8.xls]

\section{Additional File 9}

Recommended gene candidates for human retina disease loci. Click here for file

[http://www.biomedcentral.com/content/supplementary/14712164-6-40-S9.xls] 


Additional File 10
Additional methods.
Click here for file
[http://www.biomedcentral.com/content/supplementary/1471-
2164-6-40-S10.doc]

\section{Acknowledgements}

We thank Caroline Zeiss for $r d I$ mice and the Yale Keck Microarray Core (Janet Hager and Kenneth Williams) for microarray printing support. We thank Paul Lizardi, Michael Zhang, and Thomas Welte for comments, Lan Ji and Adrienne LaRue for technical assistance. This work is supported by grants EYI 3607 (XYF), EY 00785 (CJB) and EYI 3865 (CJB) from the NIH, the David Woods Kemper Memorial Foundation (CJB), the Connecticut Lions Eye Research Foundation and Research to Prevent Blindness Inc.

\section{References}

I. Barnstable C): A molecular view of vertebrate retinal development. Mol Neurobiol 1987, I:9-46.

2. Cepko CL, Austin CP, Yang X, Alexiades M, Ezzeddine D: Cell fate determination in the vertebrate retina. Proc Natl Acad Sci U S A 1996, 93:589-595.

3. Livesey FJ, Cepko CL: Vertebrate neural cell-fate determination: lessons from the retina. Nat Rev Neurosci 200I, 2: I09-I I8.

4. Zhang SS, Fu XY, Barnstable CJ: Molecular aspects of vertebrate retinal development. Mol Neurobiol 2002, 26: I37-I52.

5. Okazaki Y, Furuno M, Kasukawa T, Adachi J. Bono H, Kondo S, Nikaido I, Osato N, Saito R, Suzuki H, Yamanaka I, Kiyosawa H, Yagi K, Tomaru Y, Hasegawa Y, Nogami A, Schonbach C, Gojobori T, Baldarelli R, Hill DP, Bult C, Hume DA, Quackenbush J, Schriml LM, Kanapin A, Matsuda H, Batalov S, Beisel KW, Blake JA, Bradt D, Brusic V, Chothia C, Corbani LE, Cousins S, Dalla E, Dragani TA, Fletcher CF, Forrest A, Frazer KS, Gaasterland T, Gariboldi M, Gissi C, Godzik A, Gough J, Grimmond S, Gustincich S, Hirokawa N, Jackson IJ, Jarvis ED, Kanai A, Kawaji H, Kawasawa Y, Kedzierski RM, King BL, Konagaya A, Kurochkin IV, Lee Y, Lenhard B, Lyons PA, Maglott DR, Maltais L, Marchionni L, McKenzie L, Miki H, Nagashima T, Numata K, Okido T, Pavan WJ, Pertea G, Pesole G, Petrovsky N, Pillai R, Pontius JU, Qi D, Ramachandran S, Ravasi T, Reed JC, Reed DJ, Reid J, Ring BZ, Ringwald M, Sandelin A, Schneider C, Semple CA, Setou M, Shimada K, Sultana R, Takenaka Y, Taylor MS, Teasdale RD, Tomita M, Verardo R, Wagner L, Wahlestedt C, Wang Y, Watanabe Y, Wells C, Wilming LG, Wynshaw-Boris A, Yanagisawa M, Yang I, Yang L, Yuan Z, Zavolan M, Zhu Y, Zimmer A, Carninci P, Hayatsu N, HirozaneKishikawa T, Konno H, Nakamura M, Sakazume N, Sato K, Shiraki T, Waki K, Kawai J, Aizawa K, Arakawa T, Fukuda S, Hara A, Hashizume W, Imotani K, Ishii Y, Itoh M, Kagawa I, Miyazaki A, Sakai K, Sasaki D, Shibata K, Shinagawa A, Yasunishi A, Yoshino M, Waterston R, Lander ES, Rogers J, Birney E, Hayashizaki Y: Analysis of the mouse transcriptome based on functional annotation of 60,770 fulllength cDNAs. Nature 2002, 420:563-573.

6. Blackshaw S, Fraioli RE, Furukawa T, Cepko CL: Comprehensive analysis of photoreceptor gene expression and the identification of candidate retinal disease genes. Cell 200I, I 07:579-589.

7. Katsanis N, Worley KC, Gonzalez G, Ansley SJ, Lupski JR: A computational/functional genomics approach for the enrichment of the retinal transcriptome and the identification of positional candidate retinopathy genes. Proc Natl Acad Sci U S A 2002, 99:|4326-|433|.

8. Chowers I, Gunatilaka TL, Farkas RH, Qian J, Hackam AS, Duh E, Kageyama M, Wang C, Vora A, Campochiaro PA, Zack DJ: Identification of novel genes preferentially expressed in the retina using a custom human retina cDNA microarray. Invest Ophthalmol Vis Sci 2003, 44:3732-374I.

9. Yu J, Farjo R, MacNee SP, Baehr W, Stambolian DE, Swaroop A, Chowers I, Gunatilaka TL, Farkas RH, Qian J, Hackam AS, Duh E, Kageyama M, Wang C, Vora A, Campochiaro PA, Zack DJ: Annotation and analysis of 10,000 expressed sequence tags from developing mouse eye and adult retina Identification of novel genes preferentially expressed in the retina using a custom human retina cDNA microarray. Genome Biol 2003, 4:R65.

10. Yu J, Farjo R, MacNee SP, Baehr W, Stambolian DE, Swaroop A: Annotation and analysis of 10,000 expressed sequence tags from developing mouse eye and adult retina. Genome Biol 2003, 4:R65.

II. Wistow G, Bernstein SL, Wyatt MK, Ray S, Behal A, Touchman JW, Bouffard G, Smith D, Peterson K: Expressed sequence tag analysis of human retina for the NEIBank Project: retbindin, an abundant, novel retinal cDNA and alternative splicing of other retina-preferred gene transcripts. Mol Vis 2002. 8:196-204.

12. Swaroop $A$, Zack DJ: Transcriptome analysis of the retina. Genome Biol 2002, 3:REVIEWSI022.

13. Blackshaw S, Harpavat S, Trimarchi J, Cai L, Huang H, Kuo WP, Weber G, Lee K, Fraioli RE, Cho SH, Yung R, Asch E, Ohno-Machado $\mathrm{L}$, Wong WH, Cepko CL: Genomic analysis of mouse retinal development. PLOS Biol 2004, 2:E247.

14. Schulz HL, Goetz T, Kaschkoetoe J, Weber BH: The Retinome defining a reference transcriptome of the adult mammalian retina/retinal pigment epithelium. BMC Genomics 2004, 5:50.

15. Liang S, Zhao S, Mu X, Thomas T, Klein WH: Novel retinal genes discovered by mining the mouse embryonic RetinalExpress database. Mol Vis 2004, 1 0:773-786.

16. Hackam AS, Qian J, Liu D, Gunatilaka T, Farkas RH, Chowers I, Kageyama M, Parmigiani G, Zack DJ: Comparative gene expression analysis of murine retina and brain. Mol Vis 2004, I 0:637-649.

17. Burge C, Karlin S: Prediction of complete gene structures in human genomic DNA. I Mol Biol 1997, 268:78-94.

18. Ashburner M, Ball CA, Blake JA, Botstein D, Butler $H$, Cherry JM, Davis AP, Dolinski K, Dwight SS, Eppig JT, Harris MA, Hill DP, IsselTarver L, Kasarskis A, Lewis S, Matese JC, Richardson JE, Ringwald M, Rubin GM, Sherlock G: Gene ontology: tool for the unification of biology. The Gene Ontology Consortium. Nat Genet 2000, 25:25-29.

19. Chen S, Wang QL, Nie Z, Sun H, Lennon G, Copeland NG, Gilbert DJ, Jenkins NA, Zack DJ: Crx, a novel Otx-like paired-homeodomain protein, binds to and transactivates photoreceptor cell-specific genes. Neuron 1997, I9:1017-1030.

20. Furukawa T, Morrow EM, Cepko CL, Chen S, Wang QL, Nie Z, Sun H, Lennon G, Copeland NG, Gilbert DJ, Jenkins NA, Zack DJ: Crx, a novel otx-like homeobox gene, shows photoreceptor-specific expression and regulates photoreceptor differentiation Crx, a novel Otx-like paired-homeodomain protein, binds to and transactivates photoreceptor cell-specific genes. Cell 1997, $91: 53|-54|$.

21. Furukawa $\mathrm{T}$, Kozak $\mathrm{CA}$, Cepko $\mathrm{CL}$ : rax, a novel paired-type homeobox gene, shows expression in the anterior neural fold and developing retina. Proc Natl Acad Sci U S A 1997, 94:3088-3093.

22. Bovolenta $\mathrm{P}$, Mallamaci A, Briata $\mathrm{P}$, Corte G, Boncinelli E: Implication of OTX2 in pigment epithelium determination and neural retina differentiation. J Neurosci 1997, I 7:4243-4252.

23. Baas D, Bumsted KM, Martinez JA, Vaccarino FM, Wikler KC, Barnstable $C$ : The subcellular localization of Otx2 is cell-type specific and developmentally regulated in the mouse retina. Brain Res Mol Brain Res 2000, 78:26-37.

24. Dyer MA, Livesey FJ, Cepko CL, Oliver G: Prox I function controls progenitor cell proliferation and horizontal cell genesis in the mammalian retina. Nat Genet 2003, 34:53-58.

25. Cinquanta M, Rovescalli AC, Kozak CA, Nirenberg M: Mouse Sebox homeobox gene expression in skin, brain, oocytes, and twocell embryos. Proc Natl Acad Sci U S A 2000, 97:8904-8909.

26. Sharma K, Sheng HZ, Lettieri K, Li H, Karavanov A, Potter S, Westphal H, Pfaff SL: LIM homeodomain factors Lhx3 and Lhx4 assign subtype identities for motor neurons. Cell 1998, 95:817-828.

27. Sheng HZ, Zhadanov AB, Mosinger BJ, Fujii T, Bertuzzi S, Grinberg A Lee EJ, Huang SP, Mahon KA, Westphal H: Specification of pituitary cell lineages by the LIM homeobox gene Lhx3. Science 1996, 272:1004-1007.

28. Nguyen DN, Rohrbaugh M, Lai Z: The Drosophila homolog of Onecut homeodomain proteins is a neural-specific transcrip- 
tional activator with a potential role in regulating neural differentiation. Mech Dev 2000, 97:57-72.

29. Hong SK, Kim CH, Yoo KW, Kim HS, Kudoh T, Dawid IB, Huh TL: Isolation and expression of a novel neuron-specific onecut homeobox gene in zebrafish. Mech Dev 2002, I I 2:199-202.

30. Kawakami K, Ohto H, Takizawa T, Saito T: Identification and expression of six family genes in mouse retina. FEBS Lett 1996, 393:259-263.

31. Loosli F, Winkler S, Wittbrodt J: Six3 overexpression initiates the formation of ectopic retina. Genes Dev 1999, 13:649-654.

32. Carl M, Loosli F, Wittbrodt J: Six3 inactivation reveals its essential role for the formation and patterning of the vertebrate eye. Development 2002, I 29:4057-4063.

33. Li X, Perissi V, Liu F, Rose DW, Rosenfeld MG: Tissue-specific regulation of retinal and pituitary precursor cell proliferation. Science 2002, 297: I I80-II83.

34. Gouge A, Holt J, Hardy AP, Sowden JC, Smith HK: Foxn4--a new member of the forkhead gene family is expressed in the retina. Mech Dev 200I, 107:203-206.

35. Xu Q, Lee C: Discovery of novel splice forms and functional analysis of cancer-specific alternative splicing in human expressed sequences. Nucleic Acids Res 2003, 31:5635-5643.

Publish with Bio Med Central and every scientist can read your work free of charge

"BioMed Central will be the most significant development for disseminating the results of biomedical research in our lifetime. "

Sir Paul Nurse, Cancer Research UK

Your research papers will be:

- available free of charge to the entire biomedical community

- peer reviewed and published immediately upon acceptance

- cited in PubMed and archived on PubMed Central

- yours - you keep the copyright

Submit your manuscript here:

http://www.biomedcentral.com/info/publishing_adv.asp
BiolMedcentral 